\title{
Analysis of Sex Difference in the Tubular Reabsorption of Lithium in Rats
}

\author{
Yuichi UWAI ${ }^{1}$, Riku YAMAGUCHI ${ }^{1}$, Tomohiro NABEKURA ${ }^{1}$ \\ ${ }^{1}$ Department of Pharmaceutics, School of Pharmacy, Aichi Gakuin University, Nagoya, Japan
}

Received September 1, 2020

Accepted April 22, 2021

Epub Ahead of Print June 2, 2021

\begin{abstract}
Summary
Lithium is used in the treatment of bipolar disorder. We previously demonstrated that two types of transporters mediate the tubular reabsorption of lithium in rats, and suggested that sodium-dependent phosphate transporters play a role in lithium reabsorption with high affinity. In the present study, we examined sex differences in lithium reabsorption in rats. When lithium chloride was infused at $60 \mu \mathrm{g} / \mathrm{min}$, creatinine clearance and the renal clearance of lithium were lower, and the plasma concentration of lithium was higher in female rats. These values reflected the higher fractional reabsorption of lithium in female rats. In rats infused with lithium chloride at $6 \mu \mathrm{g} / \mathrm{min}$, the pharmacokinetic parameters of lithium examined were all similar in both sexes. The fractional reabsorption of lithium was decreased by foscarnet, a representative inhibitor of sodiumdependent phosphate transporters, in male and female rats when lithium chloride was infused at the low rate. Among the candidate transporters mediating lithium reabsorption examined herein, the mRNA expression of only PiT2, a sodium-dependent phosphate transporter, exhibited sexual dimorphism. The present results demonstrated sex differences in the tubular reabsorption of lithium with low affinity in rats.
\end{abstract}

\section{Key words}

Lithium • Tubular reabsorption • Sex difference • Sodiumdependent phosphate transporter $\bullet$ Rats

\section{Corresponding author}

Yuichi Uwai, School of Pharmacy, Aichi Gakuin University, 1-100, Kusumoto, Chikusa, Nagoya, 464-8650 Japan. E-mail: yuuwai@dpc.agu.ac.jp
Lithium is the gold standard treatment for bipolar disorder (Won and Kim 2017). Its therapeutic range is narrow, and plasma concentration of lithium is clinically monitored. Clinicians consider steady-state concentrations of between 0.6 and $1.2 \mathrm{mEq} / 1$ to be optimal for the maintenance of bipolar disorder and between 0.8 and $1.5 \mathrm{mEq} / \mathrm{l}$ to be ideal for the acute management of manic episodes (Finley et al. 1995). After glomerular filtration, $75 \%$ of lithium is reabsorbed by renal tubules, mainly the proximal tubules (Finley 2016). Previously, we intravenously injected lithium chloride at $25 \mathrm{mg} / \mathrm{kg}$ and $2.5 \mathrm{mg} / \mathrm{kg}$ as a bolus to rats, and showed that at least two types of transporters mediate the tubular reabsorption of lithium in rats: a low-affinity type and a high-affinity type (Uwai et al. 2018). Lithium reabsorption with low and high affinities was inhibited by acetazolamide and foscarnet, a typical inhibitor for sodium-dependent phosphate transporters, respectively (Uwai et al. 2018, Uwai et al. 2020). The molecular mechanisms underlying lithium reabsorption have not yet been elucidated in detail. In the present study, we examined sex differences in the reabsorption of lithium using Wistar/ST rats. The mRNA expression levels of the candidate transporters that mediate lithium reabsorption in the kidney cortex were also compared between both sexes.

Animals were treated in accordance with regulations of the Institutional Animal Use and Care Committee of School of Pharmacy, Aichi Gakuin University. Male and female Wistar/ST rats were from Chubu Kagaku Shizai (Nagoya, Japan). Rats were anesthetized with ethyl carbamate and $\alpha$-chloralose. 
Catheters were inserted into the femoral artery and femoral vein with polyethylene tubes (SP-31, Natsume Seisakusho, Tokyo, Japan) filled with heparin solution (50 IU/ml) for blood sampling and drug administration, respectively. Urine was collected from the urinary bladder catheterized with SP-31 polyethylene tubes. Lithium chloride (Wako Pure Chemical Industries, Osaka, Japan) in saline was infused at $60 \mu \mathrm{g} / \mathrm{min}$ or $6 \mu \mathrm{g} / \mathrm{min}$ for $2 \mathrm{~h}$. At the slow infusion of lithium chloride, mannitol (Wako Pure Chemical Industries) was infused at $750 \mu \mathrm{g} / \mathrm{min}$ to achieve a sufficient urine flow. Sodium foscarnet (Cayman Chemical Company, Ann Arbor, MI, USA) was infused at $600 \mu \mathrm{g} / \mathrm{min}$ to examine the contribution of sodium-dependent phosphate transporters to lithium reabsorption.

Bladder urine samples were collected in the final 20 min of the lithium infusion, and blood sampling was performed at its midpoint. Creatinine and phosphate concentrations in urine and plasma samples were assessed using assay kits from Wako Pure Chemical Industries. We calculated creatinine clearance $\left(\mathrm{C}_{\mathrm{cr}}\right)$ by dividing the amount of creatinine excreted into urine samples by its plasma concentration. After an appropriate dilution with $0.1 \%$ nitric acid, the concentrations of lithium in plasma $\left(\mathrm{Li} \mathrm{C}_{\mathrm{p}}\right.$ ) and urine were determined using the atomic absorption spectrometry Agilent 280Z AA (Agilent Technologies, Santa Clara, CA, USA). The renal clearance of lithium $\left(\mathrm{Li} \mathrm{CL}_{\mathrm{r}}\right)$ was calculated by dividing the urinary excretion rate of lithium by its plasma concentration. The fractional excretion of lithium was calculated by dividing $\mathrm{Li} \mathrm{CL}_{\mathrm{r}}$ by $\mathrm{C}_{\mathrm{cr}}$, and its fractional reabsorption was evaluated by subtracting the ratio from one. The urinary ratio of lithium to creatinine was calculated by dividing the amounts of lithium by those of creatinine in urine samples.
Total mRNA was extracted from the rat kidney cortex using TRIzolTM reagent (Thermo Fisher Scientific, Waltham, MA, USA). First-strand cDNA was synthesized from 100 ng of RNA using PrimeScript ${ }^{\mathrm{TM}}$ RT Master Mix (Takara Bio, Kusatsu, Japan). Real-time quantitative PCR was performed using TB Green ${ }^{\circledR}$ on a Thermal Cycler Dice Real Time System (Takara Bio, Kusatsu, Japan). Both reactions were conducted according to each manufacturer. The relative quantity of each sample was normalized to GAPDH expression levels, and each cDNA sample was tested in duplicate. The program used for quantitative PCR amplification consisted of a $30 \mathrm{~s}$ activation of Ex Taq DNA polymerase at $95{ }^{\circ} \mathrm{C}$, a $15 \mathrm{~s}$ denaturation step at $95{ }^{\circ} \mathrm{C}$, a $30 \mathrm{~s}$ annealing, and an extension step at $60^{\circ} \mathrm{C}$ (for 40 cycles), along with a final dissociation step $\left(15 \mathrm{~s}\right.$ at $95^{\circ} \mathrm{C}, 30 \mathrm{~s}$ at $60{ }^{\circ} \mathrm{C}$, and $15 \mathrm{~s}$ at $95^{\circ} \mathrm{C}$ ). The oligonucleotide sequences of primers specific for NHE3, NaPi-IIa, NaPi-IIc, PiT-2, and GAPDH are:

CACAGCCCTTGAAGCATTTGTC (forward), AAGCACAGCCTGCCTTGGA (reverse), CGGATTTGGTGTCAACCAGAGA (forward), GCAGCCCAGTATCCACGAAGA (reverse), CCAGCCCTGCAGACACGTTA (forward), GCAGTCTCAAGACAGGCACCA (reverse), GCTCTGACACGGATATGGTCCTC (forward), GAAGATGAACTGTGGCCTGGGTA (reverse), and GGCACAGTCAAGGCTGAGAATG (forward), ATGGTGGTGAAGACGCCAGTA (reverse), respectively.

Data were expressed as mean $\pm \mathrm{SD}$, and were analyzed by unpaired t-test or one-way analysis of variance followed by Scheffé's test using KaleidaGraph (Synergy Software, Reading, PA, USA). Differences were considered to be significant at $\mathrm{p}<0.05$.

Table 1. Pharmacokinetic parameters of lithium in male and female Wistar/ST rats infused with lithium chloride at $60 \mu \mathrm{g} / \mathrm{min}$.

\begin{tabular}{lcc}
\hline Parameter & Male & Female \\
\hline Number & 6 & 6 \\
Weight $(g)$ & $197 \pm 6$ & $198 \pm 5$ \\
$P_{c r}(\mathrm{mg} / \mathrm{dl})$ & $0.589 \pm 0.046$ & $0.681 \pm 0.049^{* *}$ \\
$C_{c r}(\mathrm{ml} / \mathrm{min} / \mathrm{kg})$ & $4.16 \pm 0.48$ & $2.72 \pm 0.60^{* *}$ \\
$\mathrm{Li} C_{p}(\mathrm{mEq} / \mathrm{l})$ & $1.33 \pm 0.10$ & $1.66 \pm 0.08^{* * *}$ \\
$\mathrm{Li} \mathrm{CL}_{r}(\mathrm{ml} / \mathrm{min} / \mathrm{kg})$ & $1.75 \pm 0.32$ & $0.491 \pm 0.208^{* * *}$ \\
Fractional reabsorption $\mathrm{of} \mathrm{Li}$ & $0.571 \pm 0.108$ & $0.816 \pm 0.075^{* *}$ \\
Urinary Li/creatinine $(\mu \mathrm{g} / \mathrm{mg})$ & $662 \pm 118$ & $309 \pm 111^{* * *}$ \\
\hline
\end{tabular}

Each parameter represents the mean $\pm \mathrm{SD}$. $\mathrm{P}_{\mathrm{cr}}$ : plasma creatinine concentration, $\mathrm{C}_{\mathrm{cr}}$ : creatinine clearance, Li $\mathrm{C}_{\mathrm{p}}$ : plasma concentration of lithium, Li CL : renal clearance of lithium. ${ }^{* *} \mathrm{p}<0.01$, ${ }^{* * *} \mathrm{p}<0.001$, versus male. 
Table 2. Pharmacokinetic parameters of lithium in male and female Wistar/ST rats infused with lithium chloride at $6 \mu \mathrm{g} / \mathrm{min}$ in the absence or presence of sodium foscarnet at $600 \mu \mathrm{g} / \mathrm{min}$.

\begin{tabular}{|c|c|c|c|c|}
\hline Parameter & Male (-foscarnet) & Female (-foscarnet) & Male (+foscarnet) & Female (+foscarnet) \\
\hline Number & 6 & 6 & 6 & 6 \\
\hline Weight (g) & $186 \pm 9$ & $185 \pm 7$ & $191 \pm 22$ & $184 \pm 8$ \\
\hline$P_{c r}(m g / d l)$ & $0.486 \pm 0.059$ & $0.555 \pm 0.069$ & $0.465 \pm 0.062$ & $0.524 \pm 0.045$ \\
\hline$C_{c r}(\mathrm{ml} / \mathrm{min} / \mathrm{kg})$ & $3.70 \pm 0.45$ & $3.18 \pm 0.77$ & $4.00 \pm 0.59$ & $3.09 \pm 0.33$ \\
\hline$L i C_{p}(m E q / l)$ & $0.145 \pm 0.014$ & $0.162 \pm 0.020$ & $0.111 \pm 0.014^{*}, \dagger \dagger$ & $0.125 \pm 0.019^{\dagger}$ \\
\hline $\mathrm{Li} C L_{r}(\mathrm{ml} / \mathrm{min} / \mathrm{kg})$ & $1.04 \pm 0.45$ & $0.898 \pm 0.435$ & $3.07 \pm 0.62^{* * *,+\dagger \dagger}$ & $2.48 \pm 0.34^{* * *, \dagger \dagger \dagger}$ \\
\hline $\begin{array}{l}\text { Fractional } \\
\text { reabsorption of } L i\end{array}$ & $0.720 \pm 0.103$ & $0.726 \pm 0.089$ & $0.233 \pm 0.105^{* * *, \dagger \dagger}$ & $0.196 \pm 0.086^{* *,+\dagger \dagger}$ \\
\hline $\begin{array}{l}\text { Urinary Li/creatinine } \\
(\mu \mathrm{g} / \mathrm{mg})\end{array}$ & $57.1 \pm 17.9$ & $55.2 \pm 14.9$ & $129 \pm 28^{* * *, i \dagger \dagger}$ & $135 \pm 30^{* * *,+\dagger \dagger}$ \\
\hline
\end{tabular}

Each parameter represents the mean $\pm \mathrm{SD}$. $\mathrm{P}_{\mathrm{cr}}$ : plasma creatinine concentration, $\mathrm{C}_{\mathrm{cr}}$ : creatinine clearance, $\mathrm{Li} \mathrm{C}_{\mathrm{p}}$ : plasma concentration of lithium, Li CLr: renal clearance of lithium. ${ }^{*} \mathrm{p}<0.05,{ }^{* * *} \mathrm{p}<0.001$, versus male (-foscarnet). ${ }^{\dagger} \mathrm{p}<0.05,{ }^{+++} \mathrm{p}<0.001$, versus female (-foscarnet).

Table 1 shows the pharmacokinetic parameters of lithium in rats infused with lithium chloride at $60 \mu \mathrm{g} / \mathrm{min}$. Li $\mathrm{C}_{\mathrm{p}}$ was significantly higher in female rats $(1.66 \pm 0.08 \mathrm{mEq} / \mathrm{l})$ than in male rats $(1.33 \pm 0.10 \mathrm{mEq} / \mathrm{l})$.

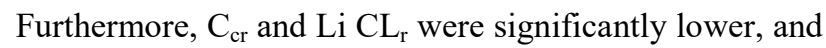
the fractional reabsorption of lithium was significantly higher in female rats. Urinary $\mathrm{Li} /$ creatinine was also significantly lower in female rats. These results suggest superior lithium reabsorption in female rats at this plasma range of lithium. The plasma concentrations of lithium in rats infused with lithium chloride at $60 \mu \mathrm{g} / \mathrm{min}$ resemble those used in clinical settings. These sex differences in lithium reabsorption may also be observed under clinical conditions.

Table 2 represents the pharmacokinetic parameters of lithium in rats infused with lithium chloride at $6 \mu \mathrm{g} / \mathrm{min}$. No significant differences were observed in any of the parameters examined between the sexes in rats not infused with foscarnet. Plasma lithium concentrations in rats infused with lithium chloride at 60 and $6 \mu \mathrm{g} / \mathrm{min}$ were similar to those in rats that received lithium chloride injections at 25 and $2.5 \mathrm{mg} / \mathrm{kg}$, respectively, as a bolus (Uwai et al. 2018, 2020). Fractional lithium reabsorption (excretion) in male rats infused with lithium chloride at 60 and $6 \mu \mathrm{g} / \mathrm{min}$ in the present study was similar to that by the low-affinity type and high-affinity type, respectively (Uwai et al. 2018, 2020). These results suggested that lithium reabsorption with low affinity was superior in female rats than in male rats.

Table 2 also shows the effects of foscarnet on the pharmacokinetic parameters of lithium. Foscarnet significantly decreased the plasma concentration of lithium and increased $\mathrm{Li} \mathrm{CL}_{\mathrm{r}}$ in each sex. The fractional reabsorption of lithium was reduced by foscarnet from 0.720 to 0.233 in male rats $(\mathrm{p}<0.001)$ and from 0.726 to 0.196 in female rats $(p<0.001)$. Urinary Li/creatinine in both sexes was increased by foscarnet. These results indicate the inhibition of lithium reabsorption by foscarnet in male and female rats. The fractional excretion of phosphate in rats infused with foscarnet was $0.887 \pm 0.122$ in males and $0.839 \pm 0.115$ in females. Eiam-ong et al. estimated that the fractional excretion of phosphate in rats infused with the Ringer-mannitol solution was 0.146 (1995), suggesting the strong inhibition of sodium-dependent phosphate transporters in rats infused with sodium foscarnet at $600 \mu \mathrm{g} / \mathrm{min}$. Using the values for the fractional reabsorption of lithium with or without foscarnet, the contribution of sodiumdependent phosphate transporters to lithium reabsorption was calculated as $67.7 \%$ in male rats and $73.0 \%$ in female rats. These values were consistent with our previous findings obtained from a bolus injection of lithium chloride at $3 \mathrm{mg} / \mathrm{kg}$ (Uwai et al. 2014). Furthermore, no sexual dimorphism was observed in the effects of foscarnet on the renal handling of lithium.

Figure 1 shows the mRNA expression levels of the candidate transporters that reabsorb lithium at the proximal tubules. Our previous findings revealed a good correlation between $\mathrm{Li} \mathrm{CL}_{\mathrm{r}}$ and the urinary excretion rate of phosphate in addition to increases in fractional lithium excretion by foscarnet and parathyroid hormone, inactivators of sodium-dependent phosphate transporters, 


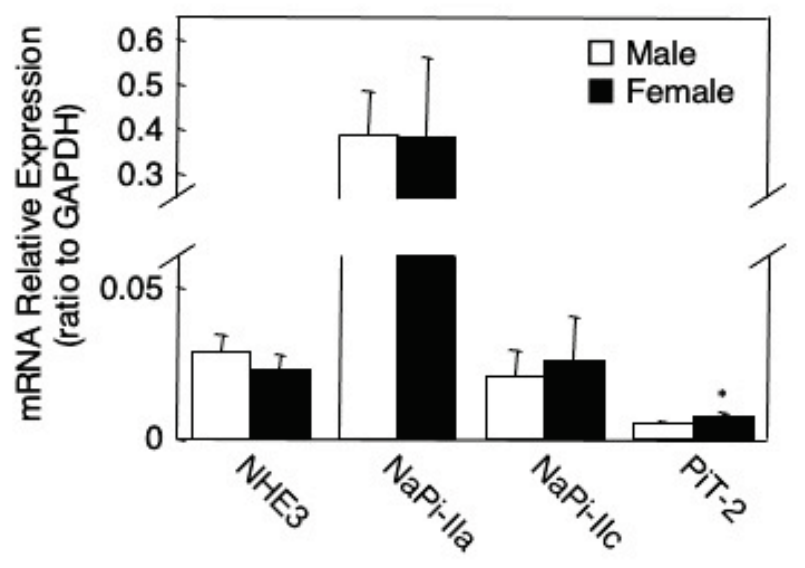

Fig. 1. mRNA expression of candidate transporters that reabsorb lithium at proximal tubules in the kidney cortex of male and female Wistar/ST rats. Relative mRNA to GAPDH was assessed by quantitative RT-PCR analysis. Each column represents the mean $+\mathrm{SD}$ of 6 rats. NHE3: $\mathrm{Na}^{+} / \mathrm{H}^{+}$exchanger 3, $\mathrm{NaPi}: \mathrm{Na} / \mathrm{Pi}$ cotransporter, PiT-2: phosphate (inorganic) transport-2, GAPDH: glyceraldehyde 3 -phosphate dehydrogenase. $* p<0.05$, versus male.

at the low plasma level of lithium in male Wistar/ST rats, suggesting that sodium-dependent phosphate transporter(s) mediate lithium reabsorption with high affinity (Uwai et al. 2014, 2018). At the proximal tubules, the sodium-dependent phosphate transporters NaPi-IIa, NaPi-IIc, and PiT-2 reabsorb phosphate filtered through the glomeruli (Biber et al. 2013). Since the mRNA expression level of PiT-2 was higher in female rats (Fig. 1) and the fractional reabsorption of lithium was similar in both sexes (Table 2), PiT-2 did not appear to significantly contribute to lithium reabsorption. It was accepted that the sodium-proton exchanger NHE3 should reabsorb lithium (Timmer and Sands 1999), and we assumed its role for the lithium reabsorption with the low affinity. Amiloride was previously shown to inhibit $\mathrm{NHE} 3$ as well as the epithelial sodium channel $\mathrm{ENaC}$ in the collecting duct, and its inhibitory effects on NHE3 were weaker than those on ENaC (Khadilkar et al. 2001, Yamamura et al. 2005). Fransen et al. (1992) reported that amiloride inhibited the reabsorption of sodium and lithium between the early distal tubules and urine, but not between the glomeruli and late proximal tubules in rats using a micropuncture experiment, suggesting the contribution of $\mathrm{ENaC}$ to lithium reabsorption. Therefore, the role of NHE3 in lithium reabsorption may be examined by administering amiloride at a markedly higher dose. A recent study demonstrated that NHE3 was not involved in lithium reabsorption using its knockout mice (Thomas et al. 2019), and no sex differences were observed in NHE3 mRNA expression levels. Therefore, further studies are needed to identify which transporter(s) reabsorb lithium at the proximal tubules.

In conclusion, the present results demonstrated sexual dimorphism in the tubular reabsorption of lithium using Wistar/ST rats. Sex differences in the renal handling of lithium in patients need to be investigated in the future.

\section{Conflict of Interest}

There is no conflict of interest.

\section{References}

BIBER J, HERNANDO N, FORSTER I: Phosphate transporters and their function. Annu Rev Physiol 75: 535-550, 2013. https://doi.org/10.1146/annurev-physiol-030212-183748

EIAM-ONG S, SPOHN M, KURTZMAN NA, SABATINI S: Insights into the biochemical mechanism of maleic acidinduced Fanconi syndrome. Kidney Int 48: 1542-1548, 1995. https://doi.org/10.1038/ki.1995.444

FRANSEN R, BOER WH, BOER P, KOOMANS HA: Amiloride-sensitive lithium reabsorption in rats: a micropuncture study. J Pharmacol Exp Ther 263: 646-650, 1992.

FINLEY PR: Drug interactions with lithium: an update. Clin Pharmacokinet 55: 925-941, 2016. https://doi.org/10.1007/s40262-016-0370-y

FINLEY PR, WARNER MD, PEABODY CA: Clinical relevance of drug interactions with lithium. Clin Pharmacokinet 29: 172-191, 1995. https://doi.org/10.2165/00003088-199529030-00004

KHADILKAR A, IANNUZZI P, ORLOWSKI J: Identification of sites in the second exomembrane loop and ninth transmembrane helix of the mammalian $\mathrm{Na}+\mathrm{H}+$ exchanger important for drug recognition and cation translocation. J Biol Chem 276: 43792-43800, 2001. https://doi.org/10.1074/jbc.M106659200

THOMAS L, XUE J, DOMINGUEZ RIEG JA, RIEG T: Contribution of NHE3 and dietary phosphate to lithium pharmacokinetics. Eur J Pharm Sci 128: 1-7, 2019. https://doi.org/10.1016/j.ejps.2018.11.008 
TIMMER RT, SANDS JM: Lithium intoxication. J Am Soc Nephrol 10: 666-674, 1999. https://doi.org/10.1681/ASN.V103666

UWAI Y, ARIMA R, TAKATSU C, FURUTA R, KAWASAKI T, NABEKURA T: Sodium-phosphate cotransporter mediates reabsorption of lithium in rat kidney. Pharmacol Res 87: 94-98, 2014. https://doi.org/10.1016/j.phrs.2014.06.012

UWAI Y, KAWASAKI T, NABEKURA T: Nonlinear disposition of lithium in rats and saturation of its tubular reabsorption by the sodium-phosphate cotransporter as a cause. Biopharm Drug Dispos 39: 83-87, 2018. https://doi.org/10.1002/bdd.2116

UWAI Y, KONDO R, SUZUKI T, KAWASAKI T, NABEKURA T: Potent inhibition of biphasic tubular reabsorption of lithium by acetazolamide and foscarnet in rats. Physiol Res 69: 645-651, 2020. https://doi.org/10.33549/physiolres.934285

WON E, KIM YK: An oldie but goodie: lithium in the treatment of bipolar disorder through neuroprotective and neurotrophic mechanisms. Int J Mol Sci 18: 2679, 2017. https://doi.org/10.3390/ijms18122679

YAMAMURA H, UGAWA S, UEDA T, SHIMADA S: Evans blue is a specific antagonist of the human epithelial $\mathrm{Na}^{+}$channel $\delta$-subunit. J Pharmacol Exp Ther 315: 965-969, 2005. https://doi.org/10.1124/jpet.105.092775 